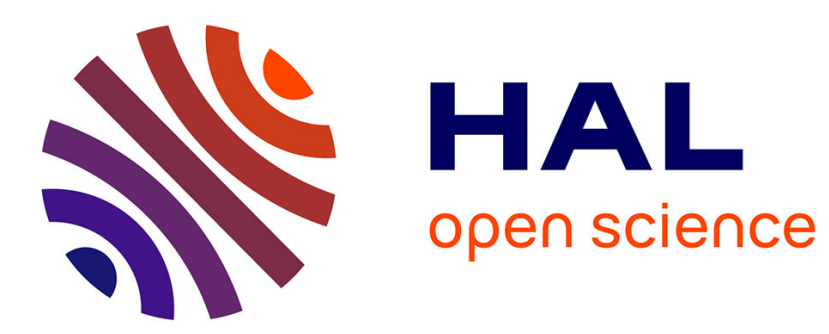

\title{
Wear mechanisms and wear rate in a high temperature dry friction of AISI H11 tool steel : influence of debris circulation
}

Olivier Barrau, Christine Boher, René Gras, Farhad Rezai-Aria

\section{- To cite this version:}

Olivier Barrau, Christine Boher, René Gras, Farhad Rezai-Aria. Wear mechanisms and wear rate in a high temperature dry friction of AISI H11 tool steel: influence of debris circulation. Wear, 2007, 263 (1-6), pp.160-168. 10.1016/j.wear.2006.12.032 . hal-01847808

\author{
HAL Id: hal-01847808 \\ https://hal.science/hal-01847808
}

Submitted on 25 Sep 2018

HAL is a multi-disciplinary open access archive for the deposit and dissemination of scientific research documents, whether they are published or not. The documents may come from teaching and research institutions in France or abroad, or from public or private research centers.
L'archive ouverte pluridisciplinaire HAL, est destinée au dépôt et à la diffusion de documents scientifiques de niveau recherche, publiés ou non, émanant des établissements d'enseignement et de recherche français ou étrangers, des laboratoires publics ou privés. 


\title{
Wear mecahnisms and wear rate in a high temperature dry friction of AISI H11 tool steel: Influence of debris circulation
}

\author{
O. Barrau ${ }^{\text {a }}$, C. Boher ${ }^{\mathrm{a}, *}$, R. Gras ${ }^{\mathrm{b}}$, F. Rezai-Aria ${ }^{\mathrm{a}}$ \\ ${ }^{a}$ Ecole des mines d'Albi-Carmaux, CROMeP, Campus Jarlard, Route de Teillet, 81013 Albi CT Cedex 09, France \\ b ISMCM-CESTI, 3 rue Ferdinand Hainaut, 93047 Saint-Ouen Cedex, France
}

\begin{abstract}
The wear rate of sliding materials seems impossible to predict. It is clearly a function of substrate material, but we are learning that many surface events are also important. In particular, studies on the last 20 years have shown that substances develop between two sliding bodies have a strong influence on both friction and wear. These substances had become known as "third bodies". Whereas third bodies have been proven to be important, they have not been completely characterized. The third bodies have been studied, but it appears that the geometries of the sliding pairs are also important.

This paper describes some experiments in which the composition of third-body materials are controlled by temperatures and in which the durability of third-body films are influenced by the geometry of contact between sliding bodies.
\end{abstract}

Keywords: Dry friction; Tribological circuit; Particles flow; Protective layers; Pin geometry

\section{Introduction}

Friction and wear are often treated as involving only the composition of the two sliding bodies. This is done particularly where modelling of friction and wear is attempted in the manner of continuum mechanics. Though friction and wear are often seen in experiments to be influenced by substances on the sliding surfaces, these quantities have not yet been property included in models.

The simplest (and unrealistic) approach in modelling is to assume that the friction force on sliding separates particles from the sliding surfaces, which particles immediately separate from the system as "wear debris". Physical observations of sliding surfaces suggest, however, that some fraction, perhaps most of the loosened particles somehow remain in the sliding interface with a few being removed from the system during continued sliding. Only these separated particles can be called "debris particles." Those remaining in the sliding region should not be considered as debris since in many instances they influence friction and

\footnotetext{
* Corresponding author. Tel.: +335634931 69; fax: +33 563493099 .

E-mail address: christine.boher@enstimac.fr (C. Boher).
}

wear rate. In fact, some loosened particles appear to act as solid lubricants. Several investigations have identified third bodies at various stages of sliding, allowing to correlate the friction, the wear and third body $[1,2,4]$.

From a fundamental point of view, the tribology of interfaces in dry friction addresses differently wear and friction. The wear mechanisms (adherence, abrasion, fatigue, ...) are substituted by the following complex sequences [2]:

- particles detachment;

- particles trapping and formation of a particle layer;

- achievement of a steady state regime of particles detachment and elimination.

This sequence differentiates the detached and the wear particles. In addition, the flow concept is introduced. The main difficulty is to find out the rheology and the behaviour of the third body that are very useful for a better understanding and predicting the life of the contacts.

In any contact, the tribological circuit [3] gathers different flows of particles that are identified inside and outside of the contact: 
- The internal source flow: is obtained by particles detachment by damage accumulation of first bodies or by inserting an artificial third body like solid lubricants.

- The internal flow: third-body circulation in the contact.

- The external flow: third-body ejection out of the contact. This flow is subdivided into two parts:

- The recirculation flow, corresponding to particles that are reinserted in the contact area.

- The wear flow, corresponding to particles that are never reinserted in the contact.

So abrasion, adhesion and delamination which are the particle detachment mechanisms, form the source flow. A steady state, in terms of the flow concept, is thus obtained when the generation and drag of particles in the contact and the elimination of particles balance: the wear depends on the trapping of third body. Among the mechanical and physicochemical parameters that control the elimination or trapping of debris, one finds the contact geometry and the compaction of the debris [4].

Three sets of experiments were done to clarify some aspects of the behaviour of third bodies. All experiments were done using steels in dry sliding. Dry sliding can be expected to produce severe wear and metallic debris. Experiments were done over a range of high temperatures in order to produce iron oxides which have often been found to produce a third-body layer with some wear ameliorating effects. Third-body materials can be expected to contain metals and oxides of the same metals.

Three variables are tested, which conditions are listed in Table 2.

a. Tests over a range of temperature from 20 to $700{ }^{\circ} \mathrm{C}$ which covers a range of oxidation rate and oxide properties.

b. Tests over a range of applied load in order to test the durability of third bodies.

c. Tests with two types of sliders, a spherical ended pin and a flat ended conical pin. These pins were expected to examine the effect of different capabilities to recycle third-body materials into the contact region.

The mechanical properties and the oxide layers, and so the sites for wear debris production change in function of tests temperatures, but this paper focuses on the third bodies flows and the debris circulation in the contact, keeping in mind these evolutions [5].

\section{Materials apparatus and experimental set-up}

\subsection{High temperature pin on disc tribometer}

The investigations are carried out with a high-temperature pin-on-disc tribometer in dry friction conditions. The tribometer complete description is reported in literature [6,7]. The disc (cylinder of $30 \mathrm{~mm}$ diameter) is heated by high frequency induction up to a maximum temperature of $800^{\circ} \mathrm{C}$. It is oxidized during $1 \mathrm{~h}$ at the test temperature (pre-oxidation). Its surface temperature is controlled by a bi-chromatic-infrared pyrometer directed towards the wear scar. During pre-oxidation, the pin is kept at room temperature (RT). After disc pre-oxidation, the pin is put on the disc and experiment can start. The pin temperature increases therefore by thermal conduction, radiation, convection and friction. During each test, friction forces are continuously recorded via a strain gauge sensor. The coulomb-friction coefficient corresponds to the macroscopic force ratio (friction force on normal constant load).

This study is only focused on damages of the pin. Disc wear mechanisms are not studied in this paper, even if disc debris intervene in third-body behaviour. SEM surface and cross-section observations of the pin are presented.

\subsection{Materials}

The pin is a double tempered martensitic steel (X38CrMoV5, AISI H11) with 5\% chromium, and the disc is a ferritic-pearlitic mild steel (XC18, AISI 1018). X38CrMoV5 steel is widely used as hot metal forming tool. The chemical compositions of the two steels are reported in Table 1. The initial hardnesses of the tool steel and the AISI 1018 steel are respectively about 472 and $168 \mathrm{HV}$ at room temperature.

\subsection{Pin geometries}

Two different pin geometries are examined. The first one has a domed-end with a radius of curvature of $20 \mathrm{~mm}$ (Fig. 1) in order to avoid flatness problem between the pin and the disc during the setting of contact. The second one has a truncated conic end with a flat circular surface of $2 \mathrm{~mm}$ diameter (Fig. 1). Both pins have an initial arithmetic roughness about $0.1 \mu \mathrm{m}$.

The worn heights " $h$ " of the pins are calculated for the two geometries as below:

- For spherical ended pin:

$$
h=\frac{2 R-\sqrt{4 R^{2}-b^{2}}}{2}
$$

$R=$ pin curvature radius $(\mathrm{mm}), b=$ diameter of the contact area after wear (mm).
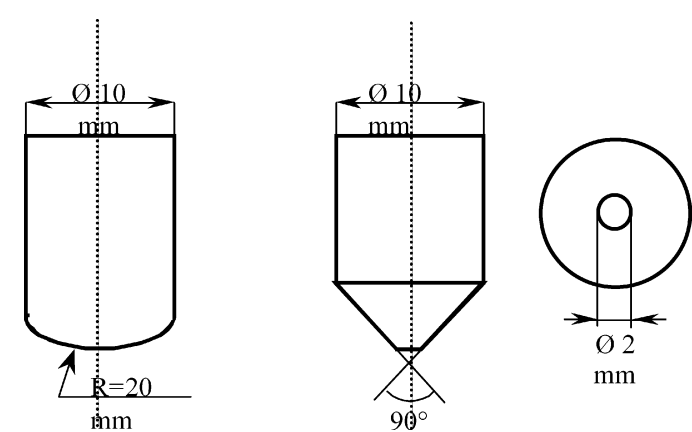

Fig. 1. Pin geometries: spherical ended pin on the left side, flat ended conical pin on the centre and bottom view of the flat pin on the right side. 
Chemical composition of test materials

\begin{tabular}{lllllllrrrr}
\hline Elements (wt\%) & C & Cr & Mn & V & Ni & Mo & Si & Pe \\
\hline Pin X38CrMoV5/AISI H11 & 0.40 & 5.05 & 0.49 & 0.47 & 0.20 & 1.25 & 0.92 \\
Disc XC18/AISI 1018 & $0.16-0.22$ & $<0.40$ & $0.40-0.70$ & - & $<0.40$ & $<0.10$ & $0.15-0.35$ & $<$ & - \\
\hline
\end{tabular}

- For flat ended conical pin:

$h=R_{\mathrm{f}}-R_{\mathrm{i}}$

$R_{\mathrm{i}}=$ initial contact surface radius of the pin $(\mathrm{mm}), R_{\mathrm{f}}=$ final contact surface radius of the pin (mm), the values $b, R_{\mathrm{i}}$ and $R_{\mathrm{f}}$ are measured with optical microscope and SEM.

\section{Experimental investigations and interpretations}

Several test conditions are studied. The influence of test temperature on debris aggregate and sintering is examined on spherical ended pins from room temperature to $800^{\circ} \mathrm{C}$ under $20 \mathrm{~N}$. Then the effect of the normal loads, ranging between 10 and $40 \mathrm{~N}$. is investigated for three temperatures $(20,500$ and $700{ }^{\circ} \mathrm{C}$ ). The role of the pin geometry (domed-end versus flat end), on the debris circulation and trapping, is only assessed at $700{ }^{\circ} \mathrm{C}$ and for normal load of $20 \mathrm{~N}$, but for different test durations. Table 2 summarizes test conditions for the experimental programs. All the tests are at least doubled to check the reproducibility of the experimental results. Table 3 gives the mean and maximal Hertz pressure for spherical ended pins. The Hertz pressures are not calculated for temperature higher than $700{ }^{\circ} \mathrm{C}$ since the Young modulus is not available. For flat ended pins, the calculated pressure is constant for all the temperatures for an initial plane on plane static contact. Initially the depth of maximum shear stress is located at $67 \mu \mathrm{m}$ under the contact point for the spherical ended pins and $640 \mu \mathrm{m}$ for flat ended pins. After the first steps of friction, the contact area of the spherical ended pin becomes a surface and the contact pressure could be considered equal to flat ended pins. After friction tests, the contact surfaces are equal for both pin geometries.

\subsection{Temperature effects}

Examination of the spherical ended pin reveals the presence of two zones in the contact region. In entrance, a compacted debris layer tends to cover the whole contact surface (Fig. 2, contact entrance is located on the right side for all the micrographs). The amount of the two zones is increasing with test temperature. Below $700^{\circ} \mathrm{C}$, less than $20 \%$ of the wear scar is covered and from $700{ }^{\circ} \mathrm{C}$, the overlap is reaching about $80 \%$, and even more for higher test temperatures. At elevated temperatures, accumulated wear debris are sintered and they form a compact layer (plate). These layer tops are further burnished or glazed and form the smooth protective layers on wear-surfaces [8]. As a result, at temperatures higher than $500^{\circ} \mathrm{C}$, friction coefficient is reduced (Table 4, Fig. 3). At high temperatures, a thick oxide layer, easily transferred from the disc on the pin surface, enhances the overlap of the contact region. Depending on the nature and thickness of oxides debris $[9,10]$, friction coefficient tends to decrease due to their low shearing resistance. For this range of temperatures, phase transformation or recrystallization are not observed on the pins.

The difference between debris aggregate and sintered debris layer should be emphasized (Fig. 4). For the first one, debris are gathered in heaps. They keep the primary shape and size of the debris. Under appropriate loading and temperature, the sintered debris layers are uniform and the primary shape and size of the debris are no more visible. The sintered debris achieves the

Table 2

Sum-up of the experimental conditions for the three experimental programs

\begin{tabular}{llll}
\hline & Pin geometry & Normal load applied $(\mathrm{N})$ & Test temperature $\left({ }^{\circ} \mathrm{C}\right)$ \\
\hline Temperature effects & Domed-end pin & 20 & $20,200,500,700,800$ \\
Normal load effects & Domed-end pin & $10,20,40$ & 3600 \\
Pin geometries effects & Domed-end pin, flat end pin & 20 & 3600 \\
\end{tabular}

Table 3

Calculated pressure for the initial point contact of the spherical ended pins and surface contact for flat ended conical pins depending on test temperatures

\begin{tabular}{|c|c|c|c|c|c|}
\hline & \multicolumn{5}{|c|}{ Test temperature } \\
\hline & $20^{\circ} \mathrm{C}$ & $200^{\circ} \mathrm{C}$ & $500^{\circ} \mathrm{C}$ & $700^{\circ} \mathrm{C}$ & \\
\hline \multicolumn{6}{|l|}{ Calculated Hertz pressure } \\
\hline Mean (MPa) & 324 & 311 & 264 & 163 & \multirow{3}{*}{ Spherical ended pins } \\
\hline $\operatorname{Max}(\mathrm{MPa})$ & 486 & 466.5 & 396 & 244 & \\
\hline Depth of the maximum shear stress, $Z(\mu \mathrm{m})$ & 67 & 73 & 84 & 104 & \\
\hline Calculated pressure $(\mathrm{MPa})$ & 6.4 & & & & \multirow{2}{*}{ Flat ended conical pins } \\
\hline Depth of the maximum shear stress, $Z(\mu \mathrm{m})$ & 1640 & & & & \\
\hline
\end{tabular}



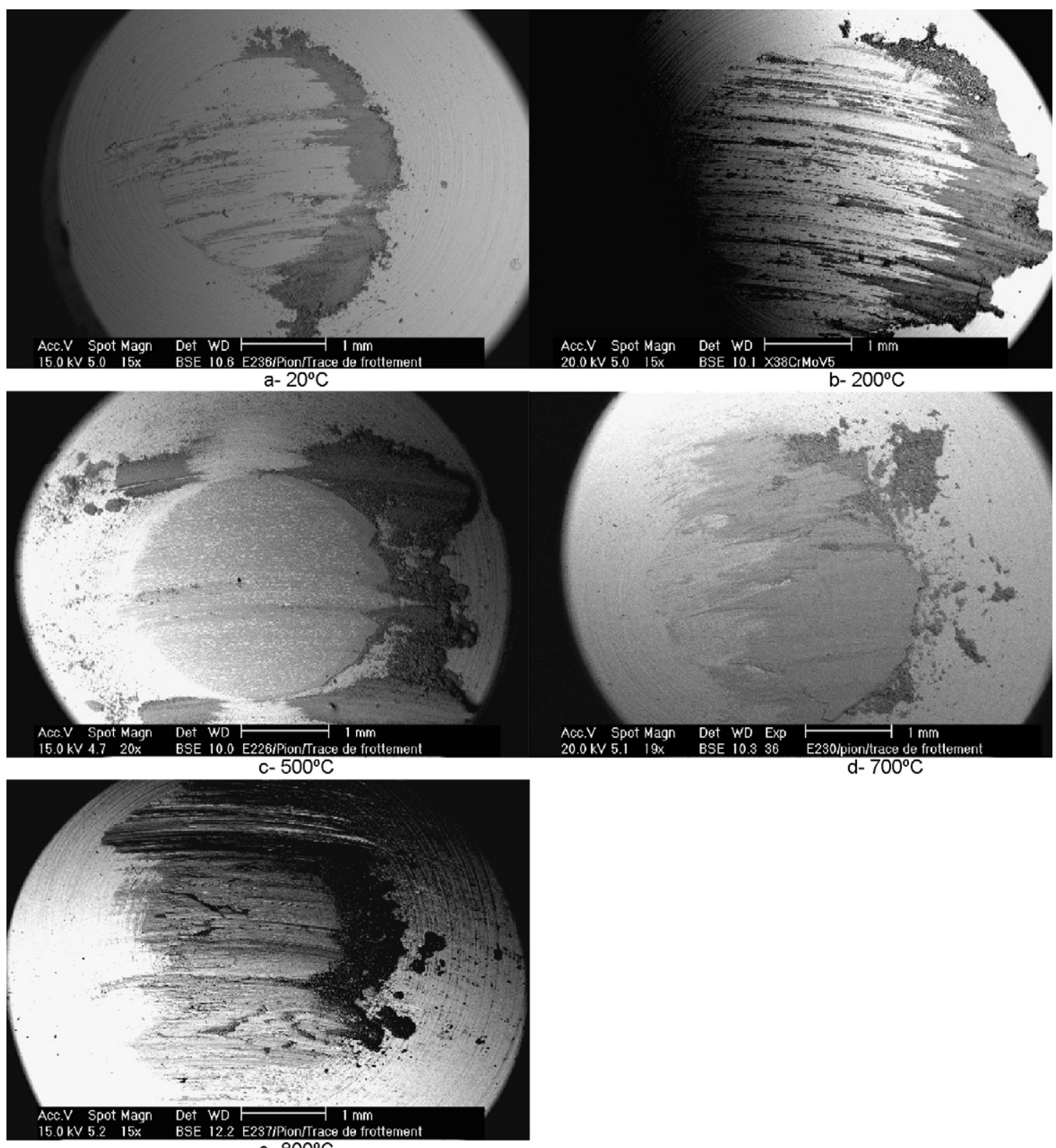

d- $700^{\circ} \mathrm{C}$

Fig. 2. Pin wear tracks from room temperature to $800^{\circ} \mathrm{C}$ under a normal load of $20 \mathrm{~N}$.

formation of burnished or glazed layers. Bonds between sintered debris are stronger than agglomerated debris and their protection against wear is more efficient.

At low temperature, abrasion is dominant and the transferred debris are developing mixed zones in the pin contact area. Since the temperature is low, the sintered layers can not be created, and so, no wear protective layer is observed. Some wear debris flows are observed for the tests performed at 20 and $200{ }^{\circ} \mathrm{C}$ (dark areas in the wear scar) and the wear scar remains mainly metallic. At $500{ }^{\circ} \mathrm{C}$, there is a balance between abrasion and

Table 4

Friction coefficient and height worn in function of the test temperatures and normal load applied

\begin{tabular}{|c|c|c|c|c|c|c|}
\hline \multirow{2}{*}{$\begin{array}{l}\text { Normal load } \\
\text { applied (N) }\end{array}$} & \multicolumn{2}{|l|}{$20^{\circ} \mathrm{C}$} & \multicolumn{2}{|l|}{$500^{\circ} \mathrm{C}$} & \multicolumn{2}{|l|}{$700^{\circ} \mathrm{C}$} \\
\hline & $\begin{array}{l}\text { Mean friction } \\
\text { coefficient, } \mu\end{array}$ & Worn height $(\mu \mathrm{m})$ & $\begin{array}{l}\text { Mean friction } \\
\text { coefficient, } \mu\end{array}$ & Worn height $(\mu \mathrm{m})$ & $\begin{array}{l}\text { Mean friction } \\
\text { coefficient, } \mu\end{array}$ & Worn height $(\mu \mathrm{m})$ \\
\hline 10 & $0.51 \pm 0.03$ & 19 & $0.50 \pm 0.02$ & 32 & $0.28 \pm 0.03$ & 40 \\
\hline 20 & $0.59 \pm 0.06$ & 43 & $0.49 \pm 0.02$ & 45 & $0.48 \pm 0.02$ & 55 \\
\hline 40 & $0.65 \pm 0.05$ & 52 & $0.47 \pm 0.03$ & 42 & $0.46 \pm 0.03$ & 49 \\
\hline
\end{tabular}




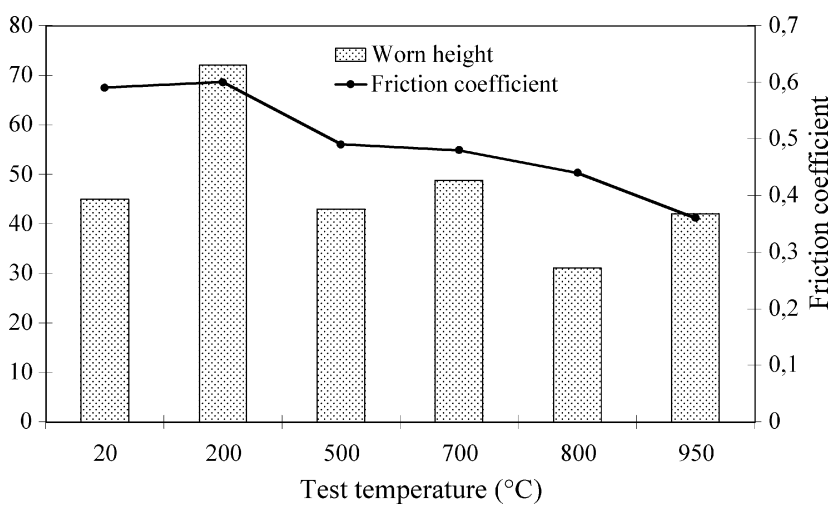

Fig. 3. Friction and wear evolution in function of test temperatures.

transfer wear mechanisms. Therefore, the wear scar is composed of "fresh steel" and transferred debris. For temperatures higher than $500{ }^{\circ} \mathrm{C}$, the quantity of thermally activated and sintered debris increases the transfer mechanism and abrasion is no more efficient to prevent the formation of wear protective layers (abrasion only concerns the transferred layers). Fig. 3 shows the calculated worn heights that show the protective effect of the transferred debris on wear. The worn heights, beyond $500^{\circ} \mathrm{C}$, should be considered as rough estimations because it is difficult to evaluate precisely the wear part which is hidden by the transferred layer (dashed columns, Fig. 3).

Always at $500{ }^{\circ} \mathrm{C}$, "whiskers" appear due to spherical ended pin geometry. This spherical geometry favours the presence of particles in the contact entrance forming "whiskers" at both sides by dragging (Fig. 2c). The feature of the "whiskers" is relative to the macroscopic pin geometry that collects debris rejected from the contact area on both sides of the disc wear scar. These "whiskers" feed into third body the outside of the contact track calculated by the theoretical contact mechanics. Thus, the formed heaps take part in the transmission of the normal load or bearing pressure. With an increase of the test temperature, more debris are compacted and sintered in the entrance of the contact, and pin wear scar looses its circular shape. Moreover, the contact zone expands perpendicularly to the friction direction that also decreases the contact pressure. In addition, the friction zone is progressively shifted to the contact entry due to the formation of compacted debris layers in this particular zone of the spherical pin.

(a)

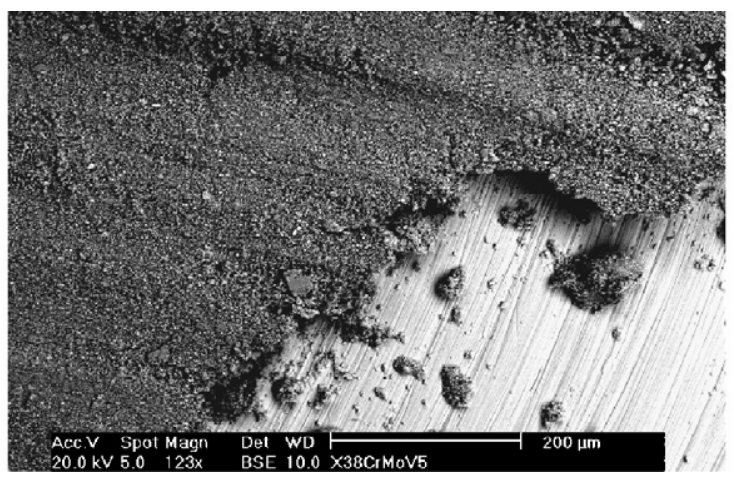

The increase of the third-body surface in the contact entrance contributes more and more for taking in charge pressure. A Combined effect of pressure at the entrance, and temperature, enhance the third-body density. Comparing the micrographs at the same temperature and different normal loads, the wear surface characteristics are similar (Figs. 2 and 8). In opposition, when temperature increases, the debris sintering is modified. The temperature contribution is more important than the pressure on the third-body behaviour and the formation of compacted layer by particles sintering. Fig. 4a shows an aggregate of debris with a bad sintered structure layer (low temperature). The layer has still a granular structure. But, on the Fig. 4b, the debris layer is well sintered and forms glazed surfaces at high temperature. As example, a debris sintering is shown on cross-section in Fig. 5. Approaching the entrance of the contact, the debris sintering becomes finer due to increase of the pressure. Therefore, it becomes difficult to identify the primary shape and size of the particles (lost of the granular aspect). Due to pressure in the contact area and also temperature, the sintered debris tend to form an uniform layer.

\subsection{Normal loading and temperature coupled effects}

In order to investigate the load influence on formation of wear protective layers, the applied normal loads are modified in function of several temperatures. The results obtained in term of friction coefficient and worn height are summarized in Table 4 and Figs. 6 and 7.

At room temperature, friction coefficient increases with normal load. This friction increase is linked to the multiplication of micro-contacts due to the initial metal on metal contact, and also, the lack of wear protective layer at this temperature. At $500^{\circ} \mathrm{C}$, the friction coefficients are quite similar under various loadings. At $700{ }^{\circ} \mathrm{C}$ and $10 \mathrm{~N}$ normal load, the measured friction coefficient is particularly low. One may conclude that the oxides layers take in charge shearing stresses, however disc surface observations reveal a metal/metal contact surface. At this temperature, stiffness and yield stress with no work hardening of asperities becomes lower (an elasto-perfect plastic behaviour). So, under such loading and temperature conditions, micro-contacts could behave as elasto-plastic behaviour (maximal Hertz pressure is $244 \mathrm{MPa}$ and the yield stress is about $242 \mathrm{MPa}$ ). For higher load-

(b)

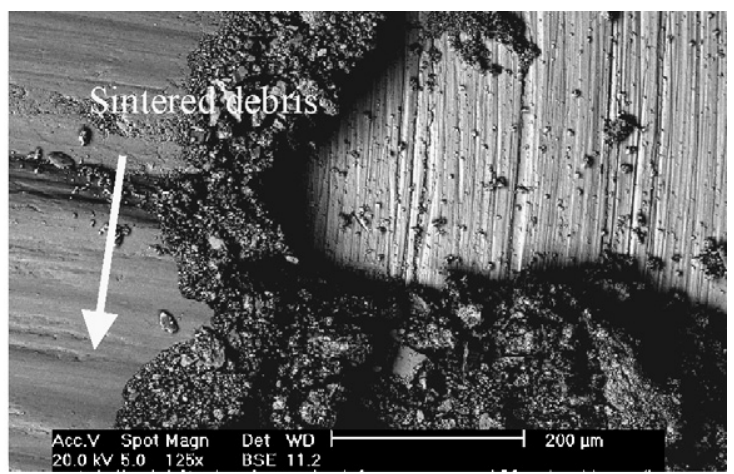

Fig. 4. Comparison of debris aggregate and sintering in function of test temperatures. (a-left) Debris aggregate $\left(200^{\circ} \mathrm{C}\right)$; (b-right) debris sintering and plate formation on the left side $\left(800^{\circ} \mathrm{C}\right)$. 


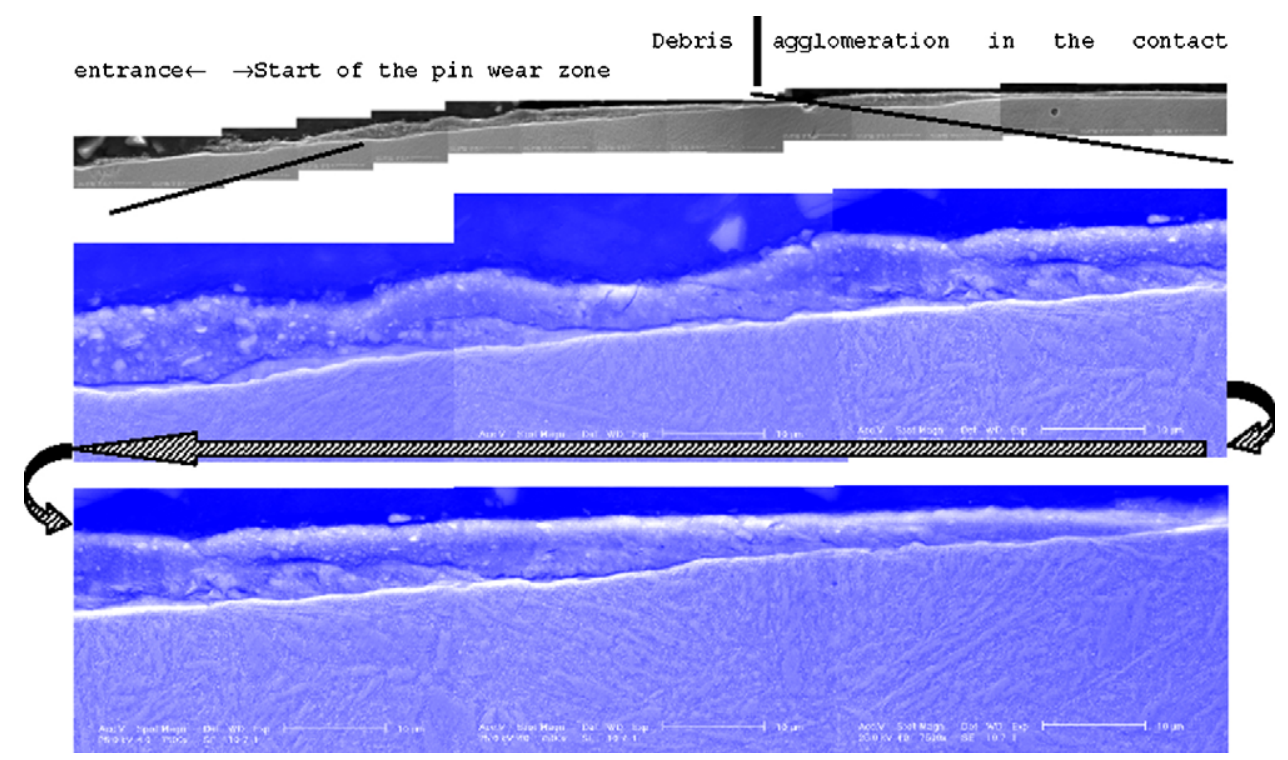

Fig. 5. Cross section observations of the debris sintering and agglomeration in the entrance of the wear track out of the contact zone (20 N).

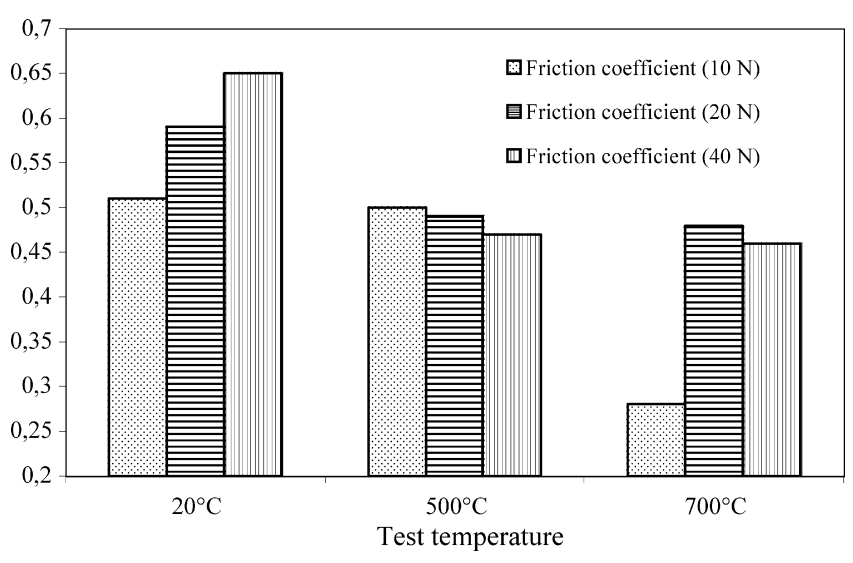

Fig. 6. Comparison of friction coefficient in function of normal loads and test temperatures.

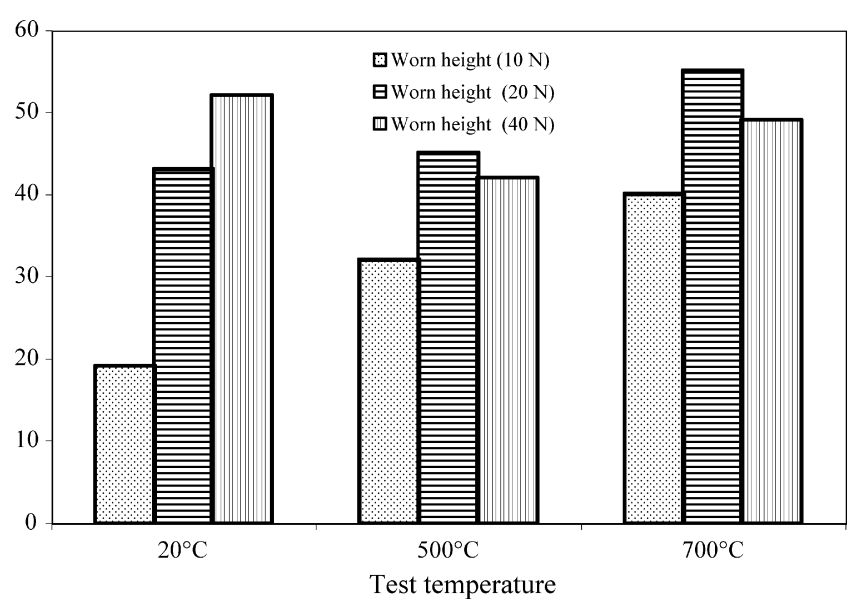

Fig. 7. Comparison of worn heights in function of normal load and test temperature. ings, maximum Hertz pressure increases beyond the yield stress and the micro contacts behaviour is strictly plastic.

At $20^{\circ} \mathrm{C}$, the transfer effects are reduced in comparison with higher temperatures. Like $20 \mathrm{~N}$ loading tests, debris are badly compacted and do not form wear protective layers (Fig. 8a and b). The abrasive mechanism is dominating and the height loss is proportional to the applied normal load due to the absence of oxides on the disc surface. So, the measured wear is directly linked to normal load. At $500^{\circ} \mathrm{C}$ (Fig. 8c and d), "whiskers" are observed like $20 \mathrm{~N}$ tests. For $10 \mathrm{~N}$ loading, a debris-bed interconnects the "whiskers" which are easily identified on Fig. 8c by they burnished aspects. At $700^{\circ} \mathrm{C}$, the wear protective layers cover most of the contact surface of the pin for both loading of 10 and $40 \mathrm{~N}$, like $20 \mathrm{~N}$ tests. Except at room temperature, the height loss is not directly linked to the applied normal load since for example the wear height is lower under $40 \mathrm{~N}$ than $20 \mathrm{~N}$ at both 500 and $700^{\circ} \mathrm{C}$. So, The increase of the applied normal load, and more precisely the contact pressure, might contribute to development of wear protective layers by debris trapping in the wear track. However, further experiments are required to better examine this load effect.

\subsection{Pin geometry effects}

The effect of pin geometry on the wear behaviour - in particular on the development of wear protective layers - is assessed. Two different pin geometries are examined (Fig. 1). These tests are performed under $700^{\circ} \mathrm{C}$, since wear protective layers on spherical ended pins are always observed at this temperature. Several tests are performed under different test durations to measure wear kinetic for both pin geometries. The mean values of friction coefficient for domed-end and flat ended pins are in the same order of magnitude, respectively, 0.49 and 0.47 . However, under the same time sampling, some differences exist in wear behaviour (Fig. 9). For the spherical ended pins, the friction 


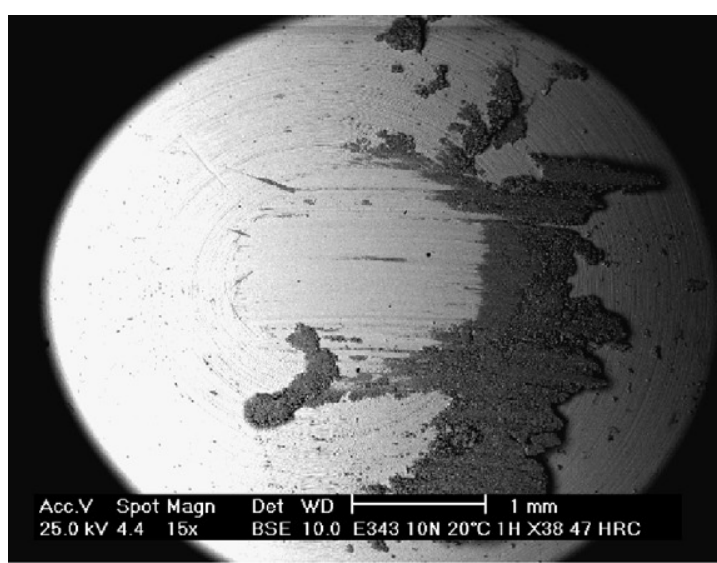

a $-10 \mathrm{~N}-20^{\circ} \mathrm{C}$

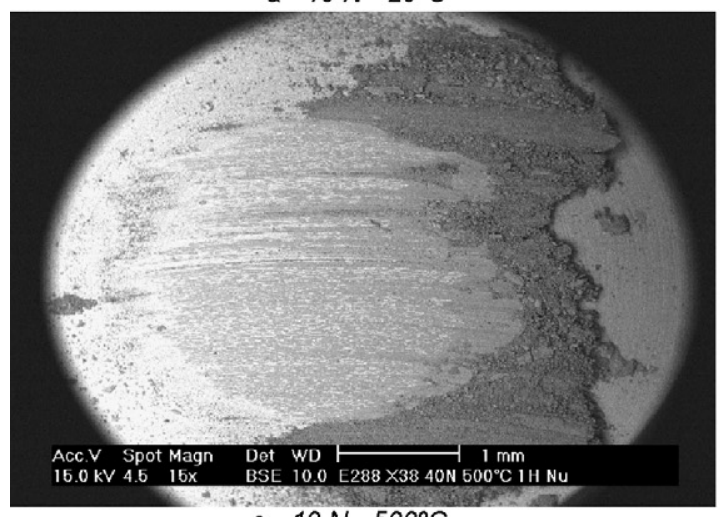

C $-10 \mathrm{~N}-500^{\circ} \mathrm{C}$

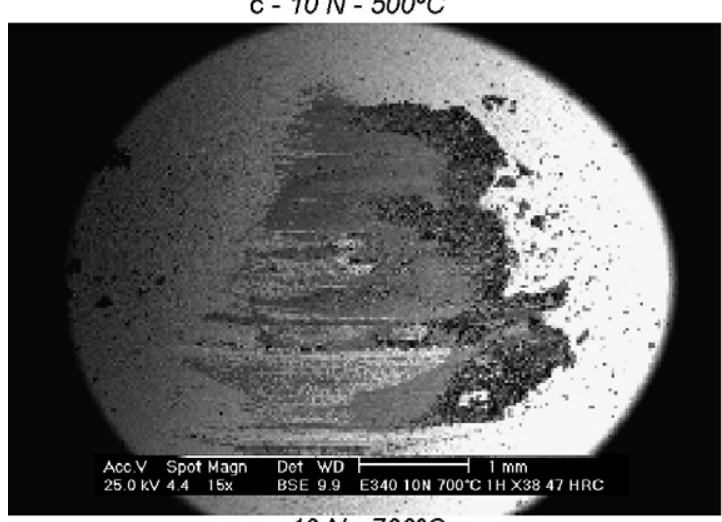

e $-10 \mathrm{~N}-700^{\circ} \mathrm{C}$

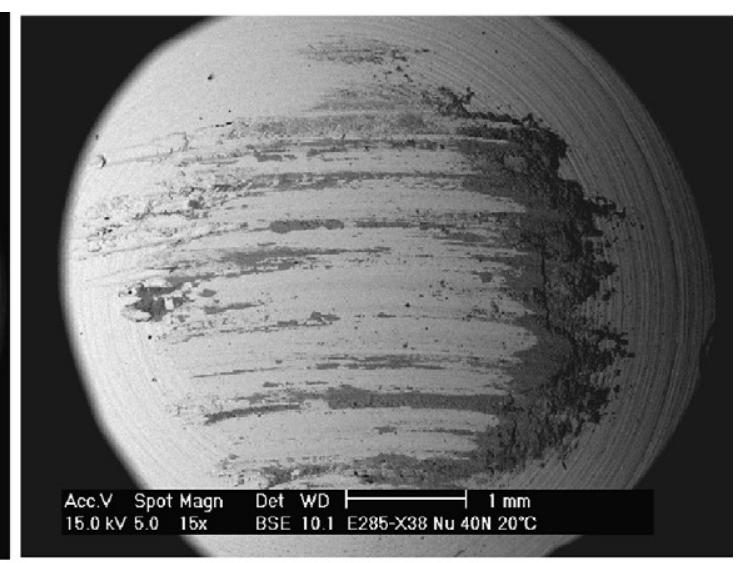

b $-40 \mathrm{~N}-20^{\circ} \mathrm{C}$

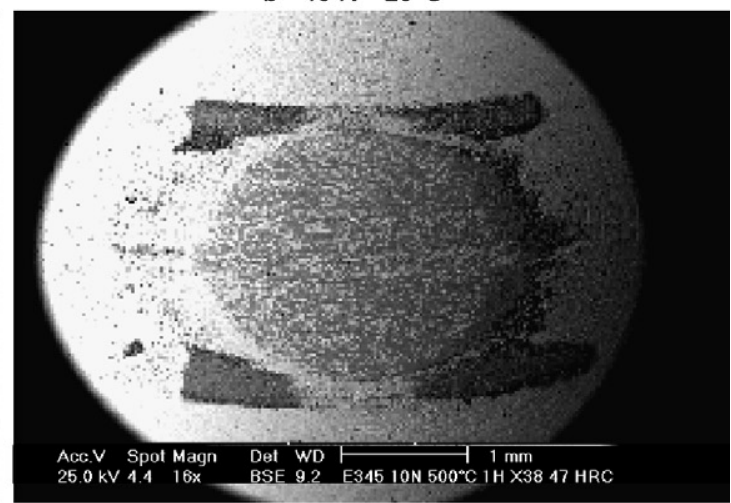

d $-40 \mathrm{~N}-500^{\circ} \mathrm{C}$

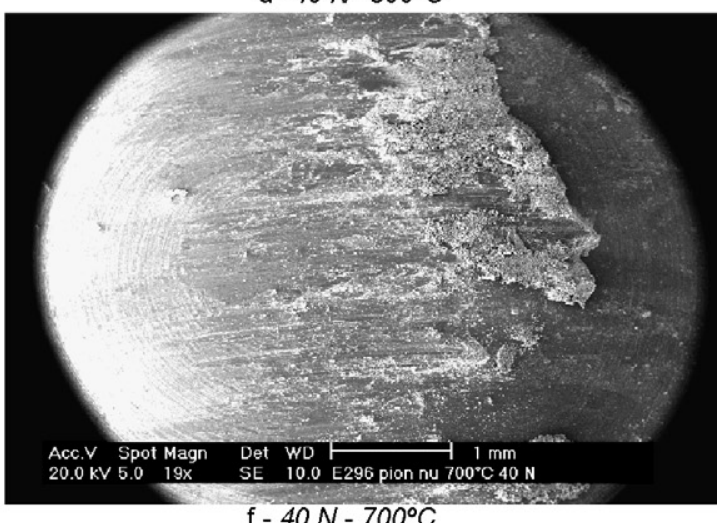

f - $40 \mathrm{~N}-700^{\circ} \mathrm{C}$

Fig. 8. Pin wear scars from room temperature to $700{ }^{\circ} \mathrm{C}$ under 10 and $40 \mathrm{~N}$ loadings.

versus time evolution presents higher fluctuations due to formation and damage of wear protective layers and the circulation of third body in the contact, as mentioned above. The release of compacted debris from the wear protective layers could therefore explain variations in the friction coefficient. In opposition, the friction vs. time curve of flat ended pins is quite smooth and more regular. This is due to the lack of recirculating debris in this case. For flat ended pins, the third body is trapped on the contact zone and all debris, ejected from the contact are definitively lost. Therefore, the recirculation flows is almost nil. A steady state regime is obtained after a few seconds of friction. The difference in friction curves is an expression of the difference in the wear mechanisms [11].

The different features of wear tracks also reveal this difference in wear mechanisms. As shown in Fig. 10, no wear protective layers are found on flat ended pins while on spherical ended pins formation of protective layers is evident (Fig. $2 \mathrm{~d}$ at $700^{\circ} \mathrm{C}$ ). In contact entrance, third-body reservoir is not observed on flat ended pins. Apparent contact surfaces are quite similar on both geometries after 1-h tests. Under prescribed test conditions and the same material examined, the presence of a bevel in the pin geometry modifies the feeding of the third body. In this case, friction and wear are resulting from contact geometry [12]. In Fig. 11a, the mixed zone, composed of transferred debris and metallic matrix, is observed. The same mixed zone is also observed on the spherical ended pins at $500{ }^{\circ} \mathrm{C}$ (Fig. 2c). In clear zones, presented in Fig. 11b, the metallic matrix is abraded without the presence of any wear protective layers. The plane pin wear tracks exhibit the same characteristics for all test durations. On the contrary, the spherical ended pins develop wear 


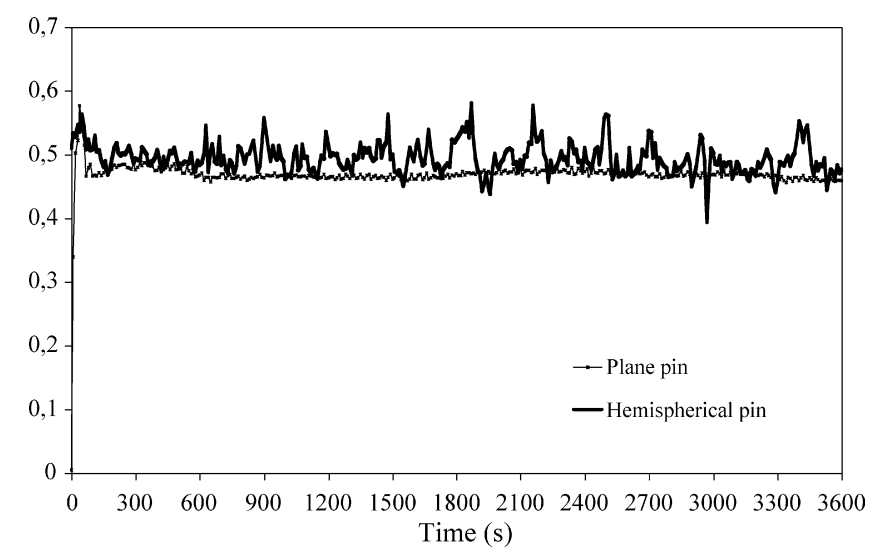

Fig. 9. Comparison of friction curves between flat ended conical pin and spherical ended pin, respectively, $0.47 / 0.49$ for the mean value (same sampling).

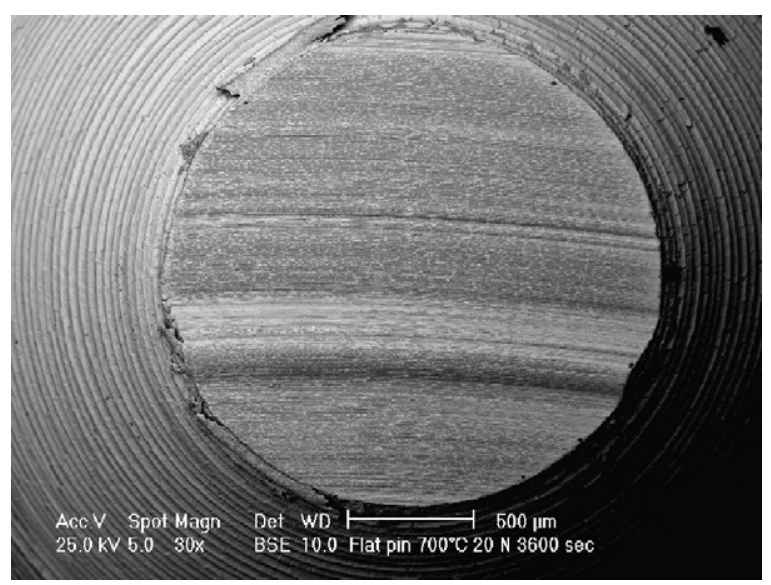

Fig. 10. Overview of flat pin wear track after $1 \mathrm{~h}$ of dry friction at $700^{\circ} \mathrm{C}$.

protective layers. So, one could conclude that only one dominant wear mechanism is activated during dry friction at $700{ }^{\circ} \mathrm{C}$ on the flat ended pins. On the other hand, the spherical ended pins are firstly abraded and then develop wear protective layers because of an important recirculation flow of debris in the contact area. Therefore, in domed pins two wear mechanisms follow one another.

(a)

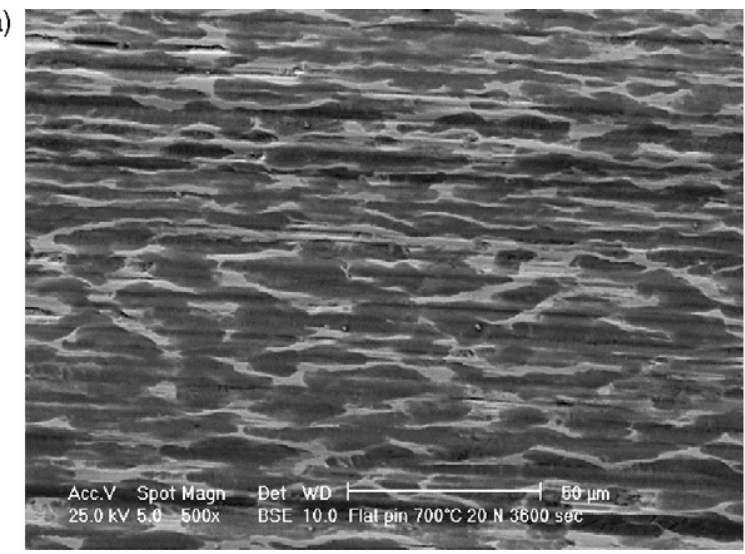

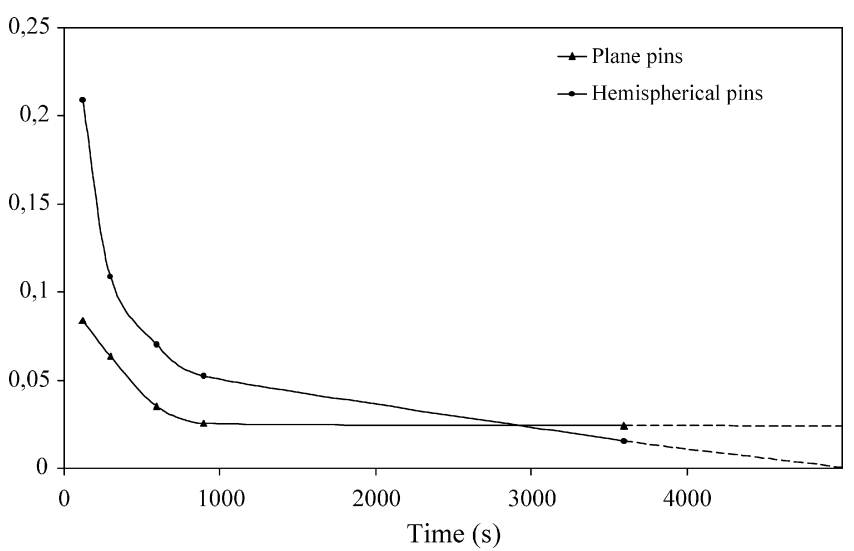

Fig. 12. Wear kinetics for both pins in function of test durations for dry friction tests at $700^{\circ} \mathrm{C}$ under a normal loading of $20 \mathrm{~N}$.

Wear kinetics measured at different test durations (Fig. 12) also support that wear mechanism are different due to the pin geometry. For short time tests, the wear rates are important for both pins because of the smoothing of surface asperities. But, the wear rate is more important for the spherical ended pins due to an initial point contact that enhances the stresses. When friction reaches a steady state regime, after $120 \mathrm{~s}$, the spherical ended pins presents a decreasing wear rate. The growth of protective layers on the pin surface prevents wear of the pin metallic matrix. In opposition, the steady state wear rate is constant in the case of the flat ended pins because wear debris are ejected from the contact area and have not the possibility to form wear protective layers. Only, abrasion wear mechanism occurs on flat ended pins.

\section{Discussion}

From the first tests results, one can conclude that the temperature contribution is more important than the pressure one on the third-body behaviour and the formation of compacted layer by particles sintering. For a given temperature, the wear scars are quite similar whatever the normal load. In opposition, for a normal load given, the wear scar changes with the temperature

(b)

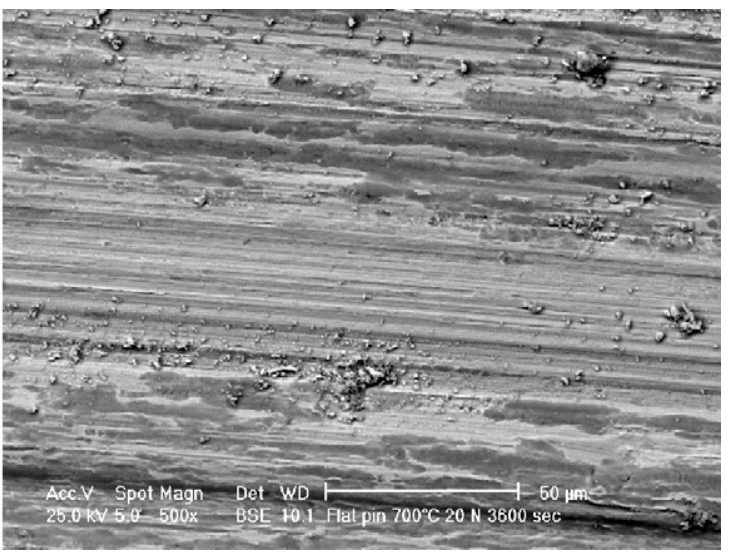

Fig. 11. Flat ended conical pin wear scar after $1 \mathrm{~h}$ of dry friction at $700^{\circ} \mathrm{C}$. (a-left) Transferred debris/metallic matrix mixed zone; (b-right) high metal abrasion in the clear zone. 
due to the development of third-body layer in the contact zone.

For static contact, contact pressure distributions caused by these two geometries are quite different. When friction begins, wear rate of the spherical ended pin is important and it is linked to high contact pressures. The initial contact point of spherical ended pin transforms into a flat surface contact inducing contact pressure decrease and the increase of the maximum shear stress depth. The value of the mean pressure could be considered as the same for the two pin geometries after a few seconds of friction. In this case, the contact pressure distribution is no more significant on third-body flow compared to the effect of pin geometry on the debris flow. Experimentally, after $120 \mathrm{~s}$ of friction, the contact surface radius of the spherical ended pin is equal to the initial contact surface radius of the flat ended pin. For flat ended pin the wear rate is constant after $600 \mathrm{~s}$ of friction because the debris emission reaches a steady state and this flow is not disturbed by the formation of protective layers. In opposition, for spherical ended pin, the wear rate tends towards zero due to the development of wear protective layers produced by debris trapping into the contact. These protective layers are not observed on flat ended pin because this geometry does not allow this mechanism of debris trapping. We can add that the physical mechanisms of debris emission are the same for both pin geometries [5]. It is thus important to preserve in the contact the initially trapped particles, because the lost debris does not protect any more the first bodies from which they are emitted. The macroscopic pin geometry induces different wear behaviour whatever test temperatures. At high temperature for spherical ended pin, third-body flow ables development of glazed layers. These glazed layers are composed of sintered oxides debris. They break under high pressure and release plates debris that circulate in the contact area. This is an endless dynamic cycle by successive formation of a compacted layer and fragmentation of plates.

The third-body flow is thus geometry dependent: the geometry of the spherical ended pins provides a limited space in the contact entry that favours the debris trapping and supports the development of a debris reservoir and so, the formation of wear protective layers. The contact geometry modifies the wear kinetics in plane and hemispherical pins under the same friction conditions (normal load, sliding velocity, materials and tribometer). Transitions in wear from high rate to low rates with sliding time are always observed on hemispherical pins while it is absent in flat pins. The wear transition versus sliding time is mainly resulted from the development of wear protective layers which are formed by the compaction and sintering of wear particles on the tribo-surfaces. One can conclude that with exactly the same wear debris nature and under the same test conditions, the formation and development of wear protective layer depend only on the particles trapping in the contact.

\section{Conclusions}

The effect on wear mechanisms of debris development and circulation in contact is performed on a high temperature $\mathrm{pin} /$ disc tribometer facility. The pin is made from a hot forming tool steel X38CrMoV5 (AISI H11) at 47 HRC. The cylindrical discs of XC18 are induction heated.

In the first experimental tests, the influence of the test temperature on the formation and development of wear protective layers is examined:

- The presence of thick oxides favours the formation of wear protective layers.

- The sintering of the debris is thermally activated and the development of protective layers is faster at high temperatures.

About the second experimental tests, it could be concluded high normal loads and thus the high contact pressures favour the mechanical bonding of wear debris.

About the pin geometry influence, it is observed that the third bodies flow plays an important role on material wear resistance in dry sliding contact and the third-body flow is geometry dependent.

\section{References}

[1] S. Descartes, Y. Berthier, Rheology and flows of solids third bodies: background and application to an $\mathrm{MoS}_{1.6}$ coating, Wear 252 (2002) 546556.

[2] Y. Berthier, Frottement sec, Stage de formation COMETT: Matériaux et Tribologie, CSAMI \& IET, 3-7 May, 1993.

[3] I. Iordanoff, Y. Berthier, First steps for a rheological model for the solid third body, lubrication at the frontier, in: D. Dowson (Ed.), Leeds-Lyon Symposium on Tribology, 1999, pp. 551-559.

[4] D. Play, M. Godet, Self-protection of high wear materials, ASLE Trans. 22 (1) (1977) 56-64.

[5] O. Barrau, Friction and wear of hot work tool steels, Ph.D. Thesis Work (in French), INP de Toulouse-Ecole des Mines d'Albi-Carmaux, France, 2004.

[6] C. Vergne, C. Boher, R. Gras, Analysis of the friction and wear behavior of hot work tool scale: application to the hot rolling process, Wear 250 (2001) 322-333.

[7] O. Barrau, C. Vergne, C. Boher, F. Rezai-Aria, R. Gras, Investigations of friction and wear mechanisms of hot forging tool steels, in: Proceedings of the Sixth International Conference on Tooling, Karlstad, 2002, pp. 81-94.

[8] J. Jiang, F.H. Stott, M.M. Stack, The role of triboparticulates in dry sliding wear, Tribol. Int. 31 (5) (1998) 245-256.

[9] L.H.S. Lung, T. Heijkoop, The influence of scale on friction in hot metal working, Wear 71 (1981) 93-102.

[10] H.S. Wong, W.O. Winer, In situ engineered oxide coatings, mechanics of coatings, in: 16th Leeds-Lyon Symposium Tribology, September 5-8, 1990, pp. 73-79.

[11] P.J. Blau, The significance and the use of the friction coefficient, Tribol. Int. 34 (2001) 585-591.

[12] J.A. Williams, Wear and wear particles_-some fundamentals, Tribol. Int. 38 (2005) 863-870. 